\title{
A MORTE NA LITERATURA INFANTIL DE HANS CHRISTIAN ANDERSEN
}

\author{
Vania Kelen Belão Vagula (FCT/UNESP) \\ Renata Junqueira de Souza (FCT/UNESP)
}

Resumo: Neste artigo apresentamos brevemente a vida e a obra de Hans Christian Andersen, estabelecendo relações entre a sua trajetória desde a infância e o seu processo de formação como escritor. Discutimos algumas características de sua obra com destaque ao papel da morte como tema de seus contos e algumas inovações em sua produção com relação à literatura tradicional.

Palavras-chave: Literatura infantil, Morte, Contos Andersianos.

Abstract: In this paper we briefly present Hans Christian Andersen's life and work, establishing relations between his path (since a child) and his formation as a writer. We discuss some features of his work, highlighting the role of death as the theme of his tales and some innovations in his production with respect to the traditional literature.

Key Words: Children's Literature, Death, Andersen's tales.

\section{ANDERSEN: UM ESCRITOR (PARA CRIANÇAS)}

O autor nasceu em Odense, no dia 02 de abril de 1805, filho de um sapateiro e de uma lavadeira, pertencendo, portanto, a uma família muito humilde. Seu pai lia para ele, histórias de La Fontaine, Holberg e das "Mil e uma noites". Em sua autobiografia, Andersen (1954) ${ }^{1}$ comentou que esses foram os primeiros momentos de contato com textos literários. A infância também foi marcada pelas

1 Refiro-me, aqui, a uma tradução da autobiografia "The Faire Tale of My Life", feita por W. Glyn Jones e publicada em 1954. 
superstições de sua mãe, pelas histórias do folclore popular que Hans Christian ouvia dos internos no hospício onde seu avô vivia e onde sua avó trabalhava, e as muitas peças teatrais assistidas no teatro de Odense.

Segundo Wullschlager (2001), Andersen recebeu instrução precária em seus primeiros anos de escolarização. Aos 14 anos foi para Copenhagen almejando tornar-se bailarino ou cantor de ópera, mas era muito alto para ser bailarino e não possuía voz para ser cantor. Contudo, seus esforços foram recompensados quando Jonas Collin, membro da comissão do teatro e conselheiro do rei, passou a custear seus estudos e, aconselhar suas decisões e tornouse um de seus mais próximos amigos. Sob a proteção de Jonas Collin, Andersen entrou na escola de gramática em Slagelse, em 1822. Ele era 5 anos mais velho que os outros garotos e sabia menos que eles, tornando-se objeto de estranhamento e zombaria para os demais. Somado a isto, teve um professor muito duro, Simon Meisling, que criticava muito suas produções e o proibiu de gastar tempo com poesias e outros textos de literatura.

Contudo, mesmo diante das dificuldades, não desistiu de seus sonhos e sempre encontrou pessoas com quem pudesse trocar ideias sobre literatura, como o escritor Severin 
Ingemann e o professor Werliin, o qual intercedeu junto a Jonas Collin para que Andersen pudesse deixar a escola de gramática e "livrar-se" do professor Meisling.

Em 1827, o jovem Andersen conseguiu a permissão de Collin para deixar a escola de gramática e terminar seus estudos em Copenhagen. Em 1828, foi aceito na Universidade de Copenhagen e, em 1829, mesmo tendo sido aprovado e conseguido permissão para continuar seus estudos, não o fez, pois queria dedicar-se a escrever. Logo se tornou escritor reconhecido em vários países da Europa e, depois, do mundo. Contudo, sofria críticas severas de alguns conterrâneos, por não dominar a norma culta da gramática dinamarquesa nem se submeter aos padrões literários da época.

Segundo estudiosos da vida de Andersen como Wullschlager (2001), Bredsdorff (1993) e Menin (1999), ele foi um artista completo, tanto pela vastidão quanto pela versatilidade de sua produção:

Autobiografias (3), biografias (13), contos para crianças (156), romances (6), poemas em coletâneas (158), livros de viagem (5), peças de teatro (5 - não há muita precisão sobre esse número), correspondência de e para H. C. Andersen Reunida em coletâneas (25), diários (15), cadernos de desenhos, também em coletâneas (14), edições em fac-símile (7), esboços à caneta e recortes de 
gravuras (6). Há ainda, reproduzidos em livros, inúmeros trabalhos de recortes papper(sic) cuttings. (MENIN, 1999, p.9899, grifo do autor)

A primeira grande produção escrita de Hans Christian foi o romance $O$ improvisador, publicada em 1835, alcançando apreço na Dinamarca e Alemanha. O romance foi logo traduzido para várias línguas e consagrou Andersen como escritor de importância europeia. Ainda em 1835, escreveu seu primeiro conto destinado ao público infantil Companheiro de Viagem e publicou a coletânea de contos intitulada Contos de Fadas para Crianças. Embora inicialmente tenha direcionado os contos para o público infantil, isso foi sendo alterado com o tempo. Sem deixar de lado esse público, foi ampliando-o para pessoas de todas as idades. O próprio Andersen afirmou "repetidamente que os escrevia para toda gente e se eram lidos para crianças, os adultos também deveriam ouvi-los." (DUARTE, 1995, p. 16).

Sendo assim, em 1844 nomeou de "Fairy Tale" (Conto de fada) uma coleção de livros e, posteriormente, a alterou para "Stories" (Histórias). Continuou escrevendo até completar 156 contos. De acordo com Bredsdorff (1993), Wullschlager (2001) e Cech (2004), o autor tornou-se conhecido ao redor do mundo e se transformou em um verdadeiro ídolo para a Dinamarca. 
Diante deste breve histórico sobre Andersen, pretendemos a seguir discutir sobre sua produção literária, evidenciando elementos em seus contos, que o levaram ao sucesso. São contos publicados com muita originalidade, diferente das estruturas e temáticas dos contos de Charles Perrault ou dos Irmãos Grimm, por exemplo.

\section{CONTOS DE ANDERSEN: AUTORAIS E ORIGINAIS}

A produção dos contos de Andersen não se restringiu a coleta e reconto das narrativas da cultura popular, como foi o caso de Perrault e dos Irmãos Grimm. Hans Christian criou a maioria dos contos que escreveu.

Em relação à questão da autoria, Jurazeky (2014, p. 57) classifica seus contos como: de autoria, criados a partir de sua imaginação e, muitas vezes, de experiências vividas; recontados a partir das histórias do folclore dinamarquês que conhecera desde criança e; inspirados em objetos, pessoas ou outros textos lidos pelo escritor.

Bredsdorff (1993) e Cech (2004) ressaltam que os textos de Andersen são geniais e que ele não foi apenas um coletor de contos populares, mas um criativo escritor. Embora tenha recriado alguns contos populares, grande parte da produção é composta de histórias de autoria, tendo produzido sua própria arte de modo ímpar e original. 
Andersen também introduziu características novas modificando os ideais de herói de sua época. Muitas de suas histórias não têm no protagonista a função de resolução de problema. Vários dos contos do dinamarquês não se iniciam com "Era uma vez" nem apresentam o tradicional desfecho "e viveram felizes para sempre".

De acordo com Bredsdorff (1993), a escrita de Andersen é simples, franca e desprovida das convenções literárias da época, não se limitando às regras e padrões literários pré-definidos. O fato de usar linguagem coloquial motivou fortes críticas à sua obra, apesar do sucesso alcançado entre leitores de um número cada vez maior de países ao redor do mundo.

Andersen escreveu seus contos considerando as próprias experiências vividas, os conhecimentos adquiridos e as leituras realizadas. Foi por meio destes que ele se constituiu como homem e como escritor. Assim, de acordo com Wullschlager (2001), a dureza enfrentada por ser uma criança pobre e desajeitada, o fato de ter recebido precária educação em seus primeiros anos escolares fizeram-no dar voz, por meio de seus textos, àqueles invisíveis ou excluídos socialmente: às crianças, aos pobres, aos animais e mesmo a seres inanimados. 
Seus contos são marcados por fortes críticas à sociedade de sua época, algumas das quais - como em As Roupas Novas do Imperador - poderiam tranquilamente ser dirigidas à sociedade atual. Alternam entre exaltar e criticar a nobreza, se compararmos, por exemplo, o conto citado anteriormente e O Rouxinol e o Imperador da China. Contudo, nestes textos, há sempre um tom de sátira e nunca um caráter político. O frio, o gelo, a neve são elementos constantes em seus contos, em decorrência do próprio clima de seu país. Assim, temos A Pequena Vendedora de Fósforos, A Rainha da Neve, A Dama das Geleiras, entre outros. A sociedade, os objetos, a natureza, os espaços específicos do território dinamarquês estão presentes nestes textos.

A experiência do mundo na sua ascensão social não evita que fale de gente humilde e descreva ambientes pobres, o que não era usual na literatura dinamarquesa. [...] E para os seus contos trouxe uma multidão de personagens que a sua volta se encontravam e o país onde viveu, a Fiónia, a Zelândia, reproduzindo, em lugar da paisagem vazia do conto tradicional, uma paisagem verdadeira com sol, natureza e clima, com a flora dinamarquesa que tão bem conheceu." (DUARTE, 1995, p. 18 e 62)

O modo ímpar da escrita de Andersen não só o fez reconhecido e apreciado mundialmente, mas também 
o consagrou como um escritor de clássicos. Ao discutir a definição de clássico, Calvino (1994) menciona como características desse tipo de texto o poder de relacionar passado e presente, tornando-se atual mesmo tendo sido escrito há muito tempo. Também destaca a capacidade de suscitar diferentes leituras do mesmo texto, em momentos distintos da vida do leitor, e que tais textos possuem a capacidade de despertar sentidos "novos, inesperados e inéditos" (CALVINO, 1994, p.12) mesmo diante de textos já conhecidos.

Neste sentido, Kirchof (2014) relata uma experiência de leitura com o conto "O Patinho Feio" com alunos de um curso de graduação. Segundo ele, após discutirem o texto durante três dias de aula, o professor teve que encerrar as discussões a contragosto dos alunos que sempre encontravam "algo mais" sobre o que queriam conversar, um novo elemento para refletir. Confirma-se, dessa maneira, o poder de textos clássicos como os de Andersen, que envolvem o leitor, suscitam diferentes leituras e permanecem atuais.

A atualidade da obra de Andersen revela-se na continuidade de seu sucesso ainda nos dias atuais. Mais de 100 anos após sua morte seus contos continuam sendo lidos e atingindo o íntimo dos leitores. Os contos foram 
traduzidos para mais de 150 línguas, estando atrás apenas da Bíblia e de Shakespeare (CECH, 2004). Segundo este autor, os personagens andersianos e alguns elementos de suas histórias, já se tornaram parte do vocabulário universal da literatura.

Os temas abordados não são efêmeros. Eles perduram justamente porque se referem à essência da alma humana. Os contos podem provocar, ainda, reflexões sobre os aspectos mais diversos da vida: valores, identidade, a dualidade, aparência versus essência, do bem versus o mal, da frieza da morte versus o calor do amor que é a própria vida e, assim, segundo Duarte (1995), entre outros aspectos, contrapõem o calor do coração à frieza da razão.

De acordo com Duarte (1995), a obra de Andersen pode ser dividida em três fases: os primeiros 10 anos, marcados pela produção de peças teatrais, contos e poemas, mas ainda sem um estilo bem definido, sendo que seus primeiros contos receberam influência do Período do Romantismo, adotando um tom popular e sentimental; a segunda, marcada pelo conto trágico, com desfecho infeliz e; a terceira, onde Andersen mesclou sua vida e obra, muitas vezes usando de sátira e ironia.

Partindo da inspiração do conto popular e da narrativa tradicional, cujos 
modelos humorísticos mantém, evolui para plena liberdade e independência, numa visão mística, com requisitos mágicos, tornando as figuras mais e mais fantásticas e animando os elementos naturais. Partindo da aceitação com humildade da sugestão rica do conto popular, do conto burlesco, das fábulas, parábolas e lendas, criou a originalidade do seu conto. (DUARTE, 1995, p.62)

A vasta obra de Andersen é permeada por muitos tipos de personagens e temas. Entre as várias temáticas presentes em suas histórias, duas marcaram suas primeiras obras: crianças e a batalha entre a vida e a morte.

Em recente estudo, Jurazeky (2014, p.48-49) aponta como temas mais frequentes de Andersen: "A existência é maravilhosa"; "É preciso sofrer para vencer"; "Há forças boas que auxiliam os infelizes, porém virtuosos"; "A morte" e; "O amor não realizado".

Entretanto, embora um destes temas seja a morte, o evento morte permeia também outras temáticas como: “É preciso sofrer para vencer" e "O amor não realizado". Assim temos, por exemplo, o conto A Pequena Sereia, no qual a protagonista morre, sem conseguir realizar seu amor pelo príncipe.

A morte se apresenta como aspecto marcante nos diferentes períodos da obra de Andersen. E é sobre esse 
tema, tão polêmico, que discutiremos a seguir, mostrando como Andersen representa a morte em seus contos, e como este assunto está ligado às suas vivências e às experiências pessoais.

\section{A TEMÁTICA DA MORTE NA OBRA DE H.C. ANDERSEN}

O primeiro texto de Andersen publicado foi um poema, no ano de 1826, quando ele ainda era aluno do professor Meisling. Sucesso imediato na Alemanha, os versos falavam de uma criança à beira da morte e foram escritos do ponto de vista do próprio eu poético, ou seja, a criança. Como em grande parte das produções de Hans Christian A., esse poema foi construído a partir de fatos de sua vida e de seus próprios sentimentos. De acordo com Wullschlager (2001), quando Andersen escreveu sobre uma criança à beira da morte, não tratava apenas da mortalidade infantil, tão comum em seus dias, mas se reportava ao próprio estado de sua alma. Para este estudioso, Andersen sentia que Meisling estava tentando matar sua criatividade, seu espírito de menino, ao impor-lhe tantas proibições, impedindo-o de escrever livremente.

Depois do primeiro poema, vieram contos e, novamente, a morte se fez presente, com diferentes enfoques. Há duas abordagens muito comuns na produção literária de Andersen 
- a primeira, quando a morte é mostrada como um meio para atingir um determinado objetivo, e a segunda, quando a morte enaltece a pureza do personagem.

Vejamos a seguir tais características em alguns dos contos andersianos:

\section{MORTE COMO ELEMENTO SECUNDÁRIO OU COMO MEIO PARA UM FIM}

É comum a ocorrência de mortes com esta configuração, principalmente em contos nos quais o autor não explora o aspecto trágico da morte, mas os povoa com elementos satíricos e protagonistas que se destacam pela esperteza e não pela bravura ou firmeza de caráter. Apresentam um herói que não é politicamente correto, mas sempre se dá bem.

Assim, Andersen trabalha com uma ideia diferenciada de protagonista/ herói (Bremond, 2008), rompendo com o que era comum na literatura de sua época.

Muitas vezes o herói é, inclusive, o responsável pelas mortes, como em Nicolau grande e Nicolau pequeno, em que o personagem principal (Nicolau Pequeno), depois de presenciar mortes como a de seus cavalos, de Nicolau Grande, da avó de ambos, e de conseguir muito dinheiro

2 A concepção que temos de herói e a mesma de Claude Bremond (2008), onde a referência a herói trata do protagonista. 
usando de astúcia e esperteza diante de tais acontecimentos, convence seu rival a entrar num saco e ser lançado de uma ponte diante da promessa de conseguir riquezas. A morte do inimigo não o beneficia com dinheiro, riqueza ou poder, mas revela-se apenas como satisfação e vingança por Nicolau Grande haver, no início da história, matado o único cavalo que Nicolau Pequeno possuía.

Em O Isqueiro Mágico, a morte também tem essa função. Quando o rei e a rainha são exterminados pelo cachorro maior, que atende aos desejos do soldado (protagonista), este é privilegiado, pois a princesa fica dona do trono. Ao final, o soldado se casa com ela, tornando-se o rei, uma vez que os antigos rei e rainha estavam mortos.

\section{A MORTE DO PERSONAGEM QUE REPRESENTA O BOM E O PURO}

Diferentemente dos textos em que o amor domina a razão e a própria morte ou em que o inimigo morre, Andersen atribui uma outra função à morte. Em contos como O Soldadinho de Chumbo, A Pequena Vendedora de Fósforos, A Sombra, A Dama das Geleiras e A Pequena Sereia há personagens que morrem e representam o bom e o puro. 
- Em O Soldadinho de Chumbo, o protagonista é lançado ao fogo da lareira, juntamente com sua amada bailarina. Entretanto, no desfecho, o chumbo derretido é transformado em coração, permitindo ao leitor inferir que o amor não foi de fato destruído. A imagem do coração formado pelo chumbo pode aludir à essência do ser e ao amor.

- Uma das histórias de Andersen mais lidas ao redor do mundo é, também, uma das mais tristes e comoventes. O conto, A pequena vendedora de fósforos, narra a noite de ano novo de uma garotinha muito pobre que tenta sem sucesso vender fósforos coloridos em meio ao frio. Neste conto, Andersen destacou também a frieza e o descaso de outros personagens que não ajudam a menina. Com frio e com fome, a garota morre, após acender alguns fósforos e visualizar na chama destes, belíssimas cenas.

- O sábio é sobrepujado até a morte por sua própria sombra, em A Sombra. Contudo, neste conto, a Sombra, que se separa de seu "senhor", retornando anos depois e se impondo a este com superioridade, representa os próprios defeitos do sábio que, por não serem enfrentados e superados, terminam por derrotá-lo. Cech (2004) aponta que, nos contos em que Andersen apresentou os defeitos de caráter, como em A Sombra, ele estava, na verdade, trazendo para o nível do consciente o lado negro que permeia a vida dos seres humanos, mas que não queremos admitir.

- Em A Dama das Geleiras, depois de perseguir Rudy toda a vida, a Dama das Geleiras finalmente o mata 
e o leva para seu reino. Novamente, neste conto, o autor ressaltou que a morte não é o fim de tudo, pois "leva apenas o invólucro, não o homem" (ANDERSEN, sd., p.74). Com esses dizeres o escritor explicitou que a morte foi apenas do corpo, mas não de sua alma, que poderia desfrutar de uma outra "vida".

- A Pequena Sereia se tornou mundialmente famoso a partir da versão de Walt Disney, nele, uma sereia representa o bom e o puro. Ela está disposta a se doar e, por se manter fiel a sua pureza, prefere morrer, perdendo para sempre o amor de sua vida, do que ferir o outro. Aqui mais uma vez, Andersen trabalha com a possibilidade de uma continuidade do ser para além da morte, apontando ao final do conto a esperança para a sereiazinha que perdera sua alma, em consequência de um pacto feito por amor: “- Dentro de trezentos anos espero ser admitida no reino de Deus - disse às novas companheiras. - Pode ser que isso ocorra até antes desse prazo - sussurrou uma delas" (ANDERSEN, 1996, p.139).

A partir destes exemplos, o leitor pode ter a impressão de que o bom é "derrotado" pela morte. Contudo, segundo Anderson (2004), não se trata de uma derrota verdadeira, pois embora o mal pareça prevalecer, o protagonista não perde suas características de pureza, então seu espírito não é vencido. A vitória, de fato, para o autor, é ser digno dela, não necessariamente alcançá-la.

Neste sentido, tais desfechos fizeram muitos estudiosos 
mostrarem as semelhanças entre os percursos de alguns personagens e a trajetória do próprio autor.

Na introdução de sua autobiografia ele afirma:

Minha vida é um bonito conto de fadas, cheia de acontecimentos maravilhosos e felizes. Mesmo se, quando eu era um menino e vivia num mundo pobre e desamparado, uma boa fada me encontrasse e dissesse "Escolha seu próprio caminho na vida e o objetivo que queres alcançar, e depois, de acordo com o desenvolvimento da tua mente, e como a razão requer, vou orientá-lo e defendê-lo", meu destino não poderia ter sido dirigido de modo mais sábio e feliz. A história de minha vida vai dizer ao mundo o que ela diz a mim: - Há um Deus amoroso, que dirige todas as coisas para o melhor. (ANDERSEN, 1954, p.13, Tradução nossa)

O pensamento de um Deus amoroso que tudo conduz é incorporado em contos como:

- A Dama das Geleiras - nesta narrativa, a força que controla o frio, a neve e o gelo é personificada na figura da Dama das Geleiras. Ela é responsável pela morte principalmente daqueles que se aventuram nos Alpes gelados para passear, caçar ou peregrinar. Tendo em suas mãos Rudy, enquanto ainda era um bebê, mas não havendo conseguido levá-lo para seu reino - o reino gelado da morte - passa a perseguilo sem sucesso até a véspera de seu casamento, 
quando Rudy se lança na água para alcançar um bote que se distanciara da margem e é tomado por ela. Apesar do elemento trágico que representa a morte do protagonista, Andersen apresenta uma outra visão para o evento morte. Revela-se aqui sua formação mística e religiosa do autor, ao apresentála como perda do corpo (invólucro), mas não do ser (alma). Por outro lado, esta é revelada pelo autor como a maneira pela qual Deus usara para evitar um mal maior, que traria infelicidade ao casal de noivos, se o casamento se realizasse. Para justificar a morte de Rudy, Andersen repetiu algumas das palavras de sua autobiografia no final do conto, quando revelou como Babette, a noiva de Rudy, encontra conforto para o ocorrido: "E, à ideia de que Deus dispõe todas as coisas pelo melhor, faz-se a luz em sua alma" (ANDERSEN, sd., p.74).

- O conto A História de Uma Mãe é bastante comovente. Ele relata a trajetória de uma mãe tentando impedir que a morte leve seu filho enfermo. A mãe sai em busca do filho, disposta a encontrá-lo a qualquer custo. Assim, canta todas as canções de ninar com as quais embalara o menino para obter informações da Noite, com a mesma finalidade aquece com um abraço um pinheiro, entrega seus olhos a um lago e, seus longos cabelos à velha que cuidava da estufa onde a morte passaria com o garoto. Ao encontrarse com a morte tem a chance de reaver o filho com vida. A morte mostra para mãe que o futuro do garoto poderá ser glorioso e feliz ou desastroso e muito triste. A mãe não querendo correr o risco de 
que seu filho viesse a sofrer, deixa a morte levá-lo. 0 conto finaliza com ela pedindo: "Ó Senhor, não deis ouvidos às minhas preces, se elas forem de encontro ao Vosso desejo, que sempre há de resultar em nosso benefício! Não me escuteis, meu Deus! Não me deis ouvidos" (ANSERSEN, 1996, p.497).

Neste trecho, evidencia-se uma temática explorada por Andersen em outros contos - de que, mesmo aquilo que parece ruim num primeiro momento, pode contribuir para o bem, se confiarmos na sabedoria divina que conhece o hoje e o amanhã. Essa ideia também foi explorada como vimos anteriormente na autobiografia do autor. Andersen revela nestes contos uma tradição religiosa indicando a necessidade de confiar num poder supremo, que tudo vê, tudo sabe e tudo pode. E, embora se distancie do tradicional "viveram felizes para sempre", a morte está ligada, de certa forma, a um sentimento de felicidade que se revela como um novo começo para quem morreu e o sentimento de esperança para os personagens que perdem alguém querido.

Diante do exposto podemos dizer que os contos de Andersen que abordam a morte como temática motivam os leitores a pensar, para além de um tema polêmico - a refletir como a morte faz parte da vida e como não há como prevêla ou evitá-la.

Neste sentido, Andersen inova, tanto no desfecho quanto 
nas mensagens transmitidas. Enquanto que na maioria dos contos de fadas o leitor se depara com: "e foram felizes para sempre" e algum valor moral mais tradicional como obediência e coragem, na literatura do autor dinamarquês há formas diferenciadas para anunciar a morte, como veremos a seguir.

Em relação à figura que representa a morte,

$\mathrm{Na}$ iconografia antiga a morte é representada por um túmulo, um personagem armado com uma foice, uma divindade com um ser humano entre as mandíbulas, um gênio alado, dois jovens, um negro, o outro branco, um cavaleiro, um esqueleto, um cavaleiro, um esqueleto, uma dança macabra, uma serpente ou qualquer outro animal psicopompo (cavalo, cachorro etc.). (CHEVALIER; CHEERBRANT, 1988, p.622)

Segundo Chevalier; Cheerbrant (1988) e Propp (2002) as tradições e ritos populares influenciam as representações literárias, enquanto para Cech (2004) os elementos representados na literatura passam a fazer parte do universo popular.

Nos contos escritos por Andersen, o emissário da morte nem sempre se revela da maneira como o leitor acostumouse em outros contos ou em filmes: uma figura vestida de negro, com uma foice para ceifar a vida. No conto $O$ Jardim 
do Paraíso, este se assemelha com essa representação. Mas embora vestido de negro e portando uma foice, é uma figura masculina, um velho forte, que possui longas asas também negras. Em A História de uma mãe, este emissário se apresenta na figura de um velho, mostrado como um ser humano comum.

Já em contos como A Dama das Geleiras e A Rainha da Neve a figura que representa a morte é feminina, uma mulher com vestes brancas, sedutora e bela. Em um país onde o frio intenso pode causar a morte para os desprotegidos ou desafortunados, Andersen personifica a mesma.

Embora hoje, em uma Dinamarca abastada, o frio e a neve não sejam mais tão assustadores, não era assim na época em que o autor viveu. Diferentemente dos dias atuais, este país possuía uma grande parcela da população muito pobre e instalada em condições de vida e moradia precárias, nas quais o inverno representava grande risco. Como vimos anteriormente, o autor foi muito pobre quando criança e conheceu muito bem os perigos de invernos rigorosos. Assim, Andersen traz para seus contos alusões que mostram o poder que o frio pode exercer na vida ou na morte das pessoas. Justifica-se neste artigo o caminho tênue entre análise textual e a vida daquele considerado 
o pai da literatura infantil universal. Muitas vezes, separar ficção e realidade não é tarefa fácil, no entanto, o texto literário, quando lido ou mediado de maneira adequada, pode levar o leitor a um rico processo de humanização. Assim, os contos de Christian Andersen cumprem esse papel e perpetuam ao tempo.

\section{LER A MORTE PODE SER UM COMEÇO}

Andersen traz para vários de seus contos a morte como consequência natural da vida, mas também como uma oportunidade para superar defeitos de caráter. Em certos textos, apresenta a morte como não sendo o fim de todas as coisas ou a derrota, pois, para ele, o que realmente importa é a essência, e esta não pode ser derrotada nem destruída.

Assim, lida com as diferentes ideias que envolvem a morte, esse evento cotidiano da vida humana, mas que se faz tão difícil aceitar. Por meio de seus textos e dos episódios de morte, o autor pode suscitar a reflexão sobre a vida real das pessoas, os valores cultivados individualmente, na sociedade, as representações de morte como destruição ou recomeço. Assim, “Andersen nos oferece em suas histórias perigo, tristeza e a sombra da morte, mas também dignidade e sabedoria" (ANDERSON, 2004, p.37).

A abordagem de temas polêmicos como a morte e, muitas 
vezes, os finais tristes, não são aspectos que contribuiriam para afastar o leitor dos textos de Andersen. Eles são, na verdade, mais um elemento enriquecedor, provocando diversas possibilidades de interpretação e de reflexão a partir da leitura da obra andersiana.

Diante do exposto, ao ler os contos de Andersen, o leitor amplia seus conhecimentos prévios, tem possibilidade de interagir com outros contextos e, a morte - um tema tão temido, se torna somente um começo para o longo caminho de se formar leitor e de compreender a vida.

\section{REFERÊNCIAS:}

Andersen, H.C.A. (sd.). Contos de Andersen: O Homen de Neve e Outros Contos (Pepita de Leão Trad.). Rio de Janeiro: São Paulo.

. (1954). The fairy tale of my life. (English translation by W. Glyn Jones) Copenhagen: Nyt Nordisk Forlag - Arnold Busck.

. (1996). Hans Christians Andersen Histórias e Contos de Fadas:

obra completa. (Amado, A. Trad.) Belo Horizonte: Vila Rica Editoras Reunidas.

Anderson, Celia Catlett. (2004). Andersen's Heroes and Heroines: Relinquishing the Reward. In Harold Bloom (Org.). Hans Christian Andersen: Bloom's Modern Critical Views. Philadelphia: Chelsea House.

Bremond, Claude. (2008). Análise das possíveis narrativas. In Barthes, Roland. et. all. Análise estrutural da narrativa. Petrópolis/RJ: Vozes.

Bredsdorff, Elias (1993). Hans Christian Andersen: a biography. London: Souvenir Press.

Calvino, Ítalo (1994). Por que ler os clássicos? São Paulo: Companhia das Letras. 
Cech, Jon (2004). Hans Christian Andersen's Fairy Tales and Stories: Secrets, Swans and Shadows. In Harold Bloom(Org.) Hans Christian Andersen: Bloom's Modern Critical Views. Philadelphia: Chelsea House.

Chevalier, Jean; Cheerbrant, Alain (1988). Dicionário de símbolos: mitos, sonhos, costumes, gestos, formas, figuras, cores, números. Rio de Janeiro: José Olympio.

Duarte, Silva (1995). Andersen e sua obra. Portugal, Lisboa: Livros Horizonte.

Jurazeky, Rosana da Silva Santos (2014). Um percurso teóricometodológico para leitura de O Isqueiro Mágico e A Rainha da Neve, de Hans Christian Andersen (1805-1875). (Tese de doutorado em Educação. Faculdade de Ciências e Tecnologia, Universidade Estadual Paulista). Presidente Prudente.

Kirchof, Edgar Roberto (2014). O ensino de estratégias de leitura com contos de Hans Christian Andersen. In Informação oral fornecida por ocasião da banca de qualificação de doutorado intitulada na FCT/UNESP, em Outubro/2014.

Menin, Ana Maria da Costa Santos (1999). O Patinho Feio de Hans Christian Andersen: o abrasileiramento de um Conto para Crianças. (Tese. UNESP). ASSIS.

Propp, Vladimir (2002). As raízes históricas do conto maravilhoso. São Paulo: Martins Fontes.

Vagula, Vania Kelen Belão (2014). O ensino de estratégias de leitura com contos de Hans Christian Andersen. (Relatório de qualificação de doutorado. UNESP). Presidente Prudente.

Wullschlager, Jackie (2001). Hans Christian Andersen: The Life of a Storyteller. London, England: Pinguin Books.

Vania Kelen Belão Vagula Doutoranda do Programa de Pós-Graduação em Educação da FCT/UNESP, pesquisadora vinculada ao Centro de Estudos em Leitura e Literatura Infantil e Juvenil (CELLIJ). Mestre em Educação pela FCT/UNESP. Professora de Educação Infantil na rede Municipal de 
Presidente Prudente e Formadora do Pacto Nacional pela Alfabetização na Idade Certa pela UNESP.

Renata Junqueira de Souza Livre docente em Metodologia da Língua Portuguesa, Professora do Programa de Pós-Graduação em Educação e do Departamento de Educação da Faculdade de Ciências e Tecnologia UNESP - Campus de Presidente Prudente, coordenadora do Centro de Estudos em Leitura e Literatura Infantil e Juvenil, pesquisadora Produtividade em Pesquisa - CNPq. E-mail: recellij@gmail.com

Recebido em 18 de janeiro de 2015. Aprovado em 16 de abril de 2015. 